\title{
Agent-Based Computational Economics: Studying the Effect of Different Levels of Rationality on Inflation and Unemployment
}

\author{
Ahmed Okasha and Colin Johnson
}

\begin{abstract}
This paper presents an agent-based computational economics model (ACE) to study demand-pull and cost-push inflation. Moreover, it studies the effect of different levels of rationality on the equilibrium price and unemployment rate. The model examines three different economies. In the first economy workers choose firms randomly, in the second economy there is loyalty between workers and firms. In the last scenario workers are persistence to find jobs. Simulations show that there is a positive relationship between equilibrium price and level of rationality while there is a negative relationship with unemployment rate. Moreover, the model is able to reproduce the behaviour of demand-pull inflation and cost-push inflation without homogeneous and perfectly rational agents assumptions.
\end{abstract}

\section{INTRODUCTION}

$\mathbf{I}^{\mathrm{r}}$ $\mathrm{N}$ the real economic world, the dynamic behaviour and interactions between economic agents (for example, firms, consumers and banks) are very complicated. Economic agents are heterogeneous (i.e., different), autonomous (that is, they have no central authority that controls them), and behave irrationally. Moreover, the growing use of communication technologies affect the market mechanism itself, increasing the dynamic fluctuations of economic systems. Therefore, economic systems are becoming more complex in terms of their interdependencies. As such, economic theory and traditional econometric tools are no longer as applicable as they once were.

Economic theory assumes that agents are perfectly rational, they have full knowledge about the market mechanisms, prices, quantities supplied and demanded, current and future inflation rates, the behaviour of other agents and their expectations. In addition, agents have the computational abilities to determine all different scenarios that may occur and have the abilities to calculate the probability of each scenario occurring. The agents select the best scenario and expect that all other agents will select the planned scenarios. This assumption is unrealistic because firstly, agents do not have all knowledge about the economy and secondly, they do not have the computational power to make optimal decisions [7], [15], [17].

On the other hand, economic theory assumes that agents are homogeneous, that is, they behave in a similar way and have the same information about the economy. In fact, agents are heterogeneous; each agent has its own preferences,

Ahmed Okasha and Colin Johnson are with the Department of Computing Laboratory, University of Kent, Canterbury, UK, (email: \{aeo3, C.G.Johnson\}@ kent.ac.uk).

Ahmed Okasha is also with Department of Social-Science Computing, Cairo University, Egypt. knowledge, utilities and so on. Finally, economic theory assumes that agents are anonymous, that is, there is an auctioneer, union or invisible hand (Adam Smith) that determines the market price and then all agents, consumers and producers, must follow that price. Economic theory depends on these assumptions in order to study inflation.

An Agent-based Computational Economics models (ACE) assume that agents are heterogeneous, boundedly rational [1], [16], [18] and interact with each other. Each agent interacts and communicates with other agents in its neighbourhood. Also, agents follow simple rules in their interactions and communications. Therefore, ACE is a bottom-up study of economic phenomena, starting from the individual level. Macro-properties or macro-level regularities emerge from these interactions.

Economic theory ignores the communication and direct interaction among agents. ACE modelling provides the modellers with facilities to model social behaviours which is not an easy task when economic theories are used. Furthermore, ACE modelling gives modellers the ability to engage and model social communication skills.

This paper studies demand-pull and cost-push inflation by using the ACE modelling technique. The paper investigates the effect of different levels of rationality on the inflation and unemployment rate. Moreover, the model relaxes the homogeneity and anonymity assumptions, which are the key assumptions in economic theory when studying inflation.

This paper is organized as follows: Section 2 describes the characteristics and benefits of an agent-based computational economics model and explains assumptions underlying this approach. Section 3 describes in brief inflation and the main causes of it. Moreover, it explains demand-pull and cost-push inflation. In Section 4, bounded rationality is investigated. The ACE model is described in Section 5 while results of the simulations are explained in Section 6.

\section{Agent-Based Computational Economics MODEL (ACE)}

ACE refers to a set of computational methods which simulate how autonomous agents, interact, communicate, learn, evolve, and make complex decisions. Agents interact locally with each other and with their environment; these local interactions give rise to global regularities [7], [18]. The challenge is to explain how these global regularities arise from local interactions of autonomous agents, and to determine the rules that exhibit certain behaviour of the problem under consideration. 
This approach is in wide-spread use to study problems in economics [16]. ACE is the computational study of economic applications modelled as evolving systems of autonomous, heterogeneous, bounded rationality interacting agents [16], [17], [18], [19]. Tesfatsion [17] defined ACE as : the computational study of economies modelled as evolving systems of autonomous interacting agents. Starting from initial conditions, specified by the modeller, the computational economy evolves over time as its constituent agents repeatedly interact with each other and learn from these interactions.

The ACE models have many differences from traditional models [2], [6], [15], [18]. One of the key differences is that ACE models allow us to model complex sets of relationships that can not be explicitly modelled using traditional modelling approaches, such as differential equations, due to issues of data availability and degrees of freedom.

ACE modelling contrasts with traditional modelling. In particular, modelling interactions between agents are easier in ACE modelling than in traditional modelling.

This paper uses an ACE model to study inflation. There are several reasons for this choice. Firstly, traditional econometric modelling approaches generally assume that an economic system is initially in some sort of equilibrium state. These approaches analyse how changes in certain variables will move the system toward a new equilibrium state. Sometimes, however, the changes are derived without quantifying the equilibrium state. In contrast, ACE allows us to quantify all variables so that the modeller can compare each variable before and after an action and explore the path of each variable to its new equilibrium.

Secondly, the ACE model assumes that agents have different data and rules so they behave in different ways, even when they are in the same situation. Economic systems are one type of system that are characterized by the fact that their aggregate regularities can not be inferred simply by looking at how each individual agent behaves; the interactions play a crucial role. This kind of system is characterized by the socalled self-organization property. Traditional modelling does not provide much guidance on the studying of this type of system. By contrast, ACE allows us to study large systems of such interacting economic agents from the bottom-up [6], [7], [16], [17], [18], [19].

\section{INFLATION}

Inflation refers to a rise in the general level of prices of goods and services over time, and reducing the value of money [14]. This reduces purchasing power, it is falling. Inflation occurs when the price level rises from one period to the next. The widespread view in economics is that inflation is caused by the interaction of a set of factors which are the supply of money, output, unemployment and interest rate. In this paper we will examine two theories that aim to explain inflation.

\section{A. Demand-Pull Inflation}

Inflation that comes from an initial increase in aggregate demand is called demand-pull inflation. Demand-pull inflation occurs when the level of aggregate demand grows faster than the underlying level of supply. Inflation may arise because of an increase in exports, an increase in government expending on goods and services or an increase in the supply of money [14].

\section{B. Cost-Push Inflation}

Inflation in which price rises result from increased production costs or similar factors, rather than from customer demand, is called cost-push inflation. Rapid wage increases or rising raw material prices are common causes of this type of inflation. A situation that has been often cited as an example of cost-push inflation was the sharp rise in the price of imported oil during the 1970s, where some economists see as a major cause of the inflation experienced in the world [14].

More debates about the major reason for cost-push inflation: monetarist economists such as Milton Friedman [9] argue against the concept of cost-push inflation because increases in the cost of goods and services do not lead to inflation without the government and its central bank cooperating in increasing the money supply. The argument is that if the money supply is constant, increases in the cost of a good or a service will decrease the money available for other goods and services, and therefore the price of some those goods will fall and offset the rise in price of those goods whose prices have increased.

\section{Bounded Rationality}

This section discusses one of the main concepts that is related to ACE, namely bounded rationality. Bounded rationality is often a more realistic assumption than the perfect rationality which is a common assumption in economic theory. Zandt [20] defined bounded rationality as the bounded rationality of agents means that there are limits on their ability to communicate- formulate and send messages and read and interpret messages- and calculate with information in the brain. In other words, bounded rationality means that agents have limited information and knowledge about the environment and other agent's behaviour. Moreover, agents have not enough computational ability to make optimal decisions.

In traditional economics perfect rationality is a key assumption. Agents interact and make decision under full capabilities and full knowledge about the environment and other agents behaviour, that help to make an optimal decision. For example, Nash Equilibrium depends on agents having full knowledge about the other agents' strategies and decisions [12].

Furthermore, the assumption of perfect rationality supposes that the decision maker (agent) understands all the consequences of his actions and is able to assign a probability to each state of nature. In contrast, in the real world, it is impossible for agents to be completely rational, because they are unable to think about all events that are related to a decision. For example, the ability of agents to think about all different possible acts is limited. 
The perfect rationality model is increasingly rejected by both laboratory experiments and with economic data [2], [5], [20] because the perfect rationality assumption leads to unacceptable results. Furthermore, when researchers collect data from surveys and censuses, their models are unable to display these data.

Bounded rationality with respect to available information covers a wide range of restrictions on the behaviour of the agents. Firstly, agents do not have perfect information about their environment but rather acquire information through interaction with the environment. Furthermore, the environment may change over time due to agent actions or external influences. Secondly, agents may not know all that they want to know about the other agents in the environment. Thirdly, agents may not be able to correctly observe the decisions made by other agents.

Bounded rationality assumes that real decision makers have limits on the amount of cognitive processing that they can dedicate to a decision. More specifically, decision makers often deal with: limited time, limited resources and incomplete information [2], [5], [16], [18]. Replacing the assumption of perfectly rational agents by that of bounded rationality agents allows us to build more realistic models of agents' decision making processes. Multiple attempts have been made to model bounded rationality. Researchers such as Arthur [2], Manson [13] and Alkemade and Poutré [1], [3] focused on bounded rationality as an alternative way of thinking of perfect rationality

Arthur [4] argued that the type of rationality assumed in economics is local and deductive rationality. In general situations for economics, Arthur disputed that this assumption should be broken down for two reasons. Firstly, our rationality is bounded. Secondly, we can not fully understand the economic problem. Manson [13] used evolutionary programming to implement the theory of bounded rationality while Alkemade and Poutré [1], [3] examined different types of bounded rationality.

\section{THE MODEL}

For simplicity, the model has neither technological change nor savings or innovation. The model consists of a large number of heterogeneous and interacting agents (firms and workers) that demand and supply labour, produce and consume goods, selling and buying them. Each firm produces a single homogeneous and perishable good. Time is discrete: $\mathrm{t}=0,1,2, \ldots$. The model describes job vacancies, wage setting and trading behaviour as well as matching and bargaining, demand and price formation as endogenous processes. Furthermore, the model tests three scenarios that worker agents may follow in their job search process.

\section{A. Firms}

The model is populated with a finite number of risky (there is a probability they will go bankrupt) firms, indexed by $\mathrm{i}$. Firms produce a homogeneous, perishable good whose price is greater than zero. Labour is the sole input for production. Workers are homogeneous as far as their skills are concerned.
Firms and workers make a contract for one time period. Hence, workers must search for new jobs at each time step. Firms follow the next formula to determine how many jobs to open at time step $t$.

$$
v_{i t}=\frac{I_{i(t-1)}}{w_{i(t-1)}}
$$

where $v_{i t}$ is the number of job-openings , $I_{i(t-1)}$ is the income of firm $\mathrm{i}$ at time $\mathrm{t}-1$ and $w_{i(t-1)}$ is the contractual wage at time $t-1$. Firms use the following function to determine their output (production).

$$
q_{i t}=\alpha n_{i t}
$$

where $q_{i t}$ is the quantity of goods produced by firm i, $n_{i t}$ is the number of hired workers at time $\mathrm{t}$, and $\alpha$ is constant, it is the labour productivity.

The economy follows algorithm 1:

Algorithm 1: general events of the agent-based model

Experiment initialisation

- numW set of workers, numF set of Firms, $n$ set number of time steps

- set initial wage, income, beta and price

for $(k=0 ; k<n ;++)$

\{

// opening job process

for $(i=0 ; i<$ numF; ++$)$

\{

$v[i]=$ ceiling $($ firm $i$ income/firm $i$ wage $) ; / /$ computes vacancies // fill the jobs queue by -2 for vacancies

for $(j=0 ; j<n u m W ;++)$

\{

if $(v[i]<=j)$ then

\{

$j o b[i][j]=-1$;

\}

else

\{

$j o b[i][j]=-2$

\}

\}

// search Job

// empty firm queue

// Calculate the sum of the wages over the firms

for $(j=0 ; j<n u m W ;++)$

\{

Generate random number from uniform distribution rn.

for $(i=0 ; i<n u m F ;++)$

\{

Calculates relative probability of wage firm $\mathrm{p}$;

if $(r n<=p)$

\{

if (there is a vacancy place in the queue ) then

Queue in a selected firm

\}

// Matching process

for $(j=0 ; j<n u m F ;++)$

\{

Calculate average of Wage demanded

Set contractual wage according to the formula $3 \mathrm{w}$

// look in the queue and find workers

for $(i=0 ; i<n u m W ;++)$

\{ 


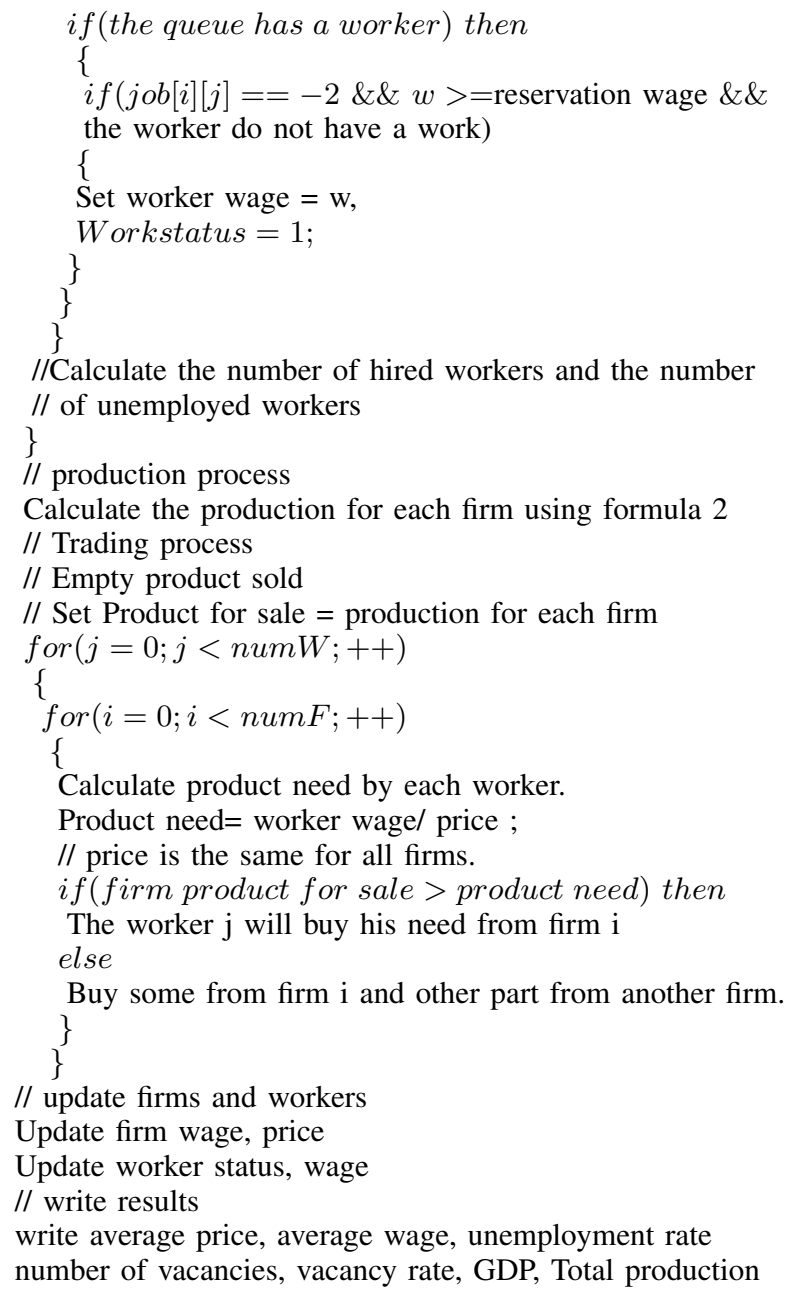

\section{B. Workers}

The model is populated with a finite number of worker agents: each worker supplies one unit of labour per period. A worker $\mathrm{j}$ enters the labour market with a desired (satisficing) wage $w_{j t}^{S}$ [8], [11], and starts to search for a new job. The workers may follows one of three different job search scenarios as stated below. If the worker finds a job he will accept this job if he earns a wage greater than the reservation wage $^{1}$ otherwise the worker becomes unemployed.

A worker/consumer $\mathrm{j}$ enters the goods market with income equals to his wage $w_{j t}$ plus any money remaining from previous periods. The worker $\mathrm{j}$ should spend all his income. If he/she is unable to do that then he/she saves money and will spend it in the next time step. The worker $\mathrm{j}$ uses his/her knowledge about the market to optimise his buying-decision. For example, if the worker $\mathrm{j}$ has full knowledge about 5 firms, then start to select a firm with the lowest price and it has still some production available to sell $q_{i t}$. If the worker $\mathrm{j}$ finds a firm with price $p_{i t}$, then he/she calculates the amount of

\footnotetext{
${ }^{1}$ The reservation wage is the lowest wage at which a worker would be willing to accept a job, which, for simplicity, we assume to be constant over time and the same for each worker.
}

goods $q_{j t}$ by dividing income by $p_{i t}$. Clearly, we have the following cases:

1) $q_{j t} \leq q_{i t}$ : then the worker achieves his maximum utility.

2) $q_{j t}>q_{i t}$ : the worker needs to look at his knowledge and find another firm to buy $q_{j t}-q_{i t}$

3) If the worker $\mathrm{j}$ still has money but there is no available goods for him, then he saves this money for the next time step.

\section{Job Search}

Each firm establishes how many vacancies it has. Workers start to search for new jobs. A worker accepts a new job only if he earns wage more than reservation wage $w^{r}$ : for simplicity the reservation wage is constant. Workers follow one of three searching scenarios available to find new jobs. In the first scenario, the worker selects one firm to visit. He selects a firm with a probability distribution based on the contractual wage, i.e., a firm that has high wage, there is a high probability for more workers to visit it and vice versa.

In the second scenario, the worker also visits only one firm, but there exists a kind of loyalty between workers and firms, i.e., if the worker was worked at a firm i, in next time step, he first visits firm i if there is an empty vacancy he queues up and asks for his desired wage (satisficing wage $w^{s}$, see equation 5, that is, the wage that a worker is willing to earn). If the firm has filled all its vacancies in their job search then he selects another firm according to the first scenario.

In the last scenario, workers are more determined to find jobs. So, each worker visits more than one firm and queues up in many queues if a worker finds more vacancies are still available. Then, the worker follows the first scenario to choose a firm to visit. Workers follow first come first served rule, i.e., if the worker sends many offers to work and receives many requests then he accept only the first request and ignore the others. The idea of proposing different scenarios for selection is to test the effect of these scenarios on the unemployment rate and inflation fluctuations.

\section{Matching and Bargaining}

After finishing search process and workers have queued up, each firm looks at its queue and calculate the current contractual wage $w_{i t}$ according to the next formula [10]:

$$
w_{i t}=\beta w_{i(t-1)}^{s}+(1-\beta) \sum_{j} w_{j(t-1)}^{s} / m_{i t}
$$

where $0 \leq \beta \leq 1$, is a parameter representing firms' power in wage bargaining. A higher $\beta$ indicates a higher force on the side of the firm in wage setting. If the $\beta=0$ this means that firms set the contractual wage is only the average of wages demanded by workers in the queue, while if $\beta=1$, firms ignore workers' desiderata when they set the contractual wage. In this paper we set $\beta=0.5, m_{i t}$ is the number of workers that have queued up for firm i at time t. The firm hires workers that accept work at this wage. When Workers do not accept jobs, or there are no more jobs available, they 
remain unemployed for this time step. Workers and firms at the end of time $t$ update their satisficing wage.

We follow Fagiolo et al. [8] in assuming that the firms and workers set their satisficing wages according to the following formulas: A firm $\mathrm{i}$ sets its satisficing wage based on the percentage $r_{i t}$ of the number of hired workers to the number of jobs positions it has opened.

$$
w_{i t}^{s}= \begin{cases}w_{i(t-1)}^{s}(1+|\gamma|), & \text { if } r_{i t}<p_{i} \\ w_{i(t-1)}^{s}(1-|\gamma|), & \text { if } r_{i t} \geq p_{i}\end{cases}
$$

where $p_{i}$ is a desired ratio of filled to open jobs $p_{i} \in(0,1]$, and $\gamma$ is a random variable distributed uniformly in $0<\gamma<$ 1 . Workers follow the following formula:

$w_{j t}^{s}= \begin{cases}\max \left(w^{r}, w_{j(t-1)}^{s}(1-|\zeta|)\right), & \text { if } \mathrm{j} \text { is unemployed } \\ w_{j(t-1)}^{s}(1+|\zeta|), & \text { if } \mathrm{j} \text { is employed. }\end{cases}$

where $w^{r}$ is the reservation wage, $\zeta$ is a random variable distributed uniformly in $0<\zeta<1$.

\section{E. Different Level of Rationality}

The ACE model examines the effect of the level of rationality on both the equilibrium price and unemployment rate. Worker agents are endowed with a certain level of knowledge, for example, a worker may have knowledge about only one firm, i.e., information about firm price and quantity available to sell. Therefore, the worker buys based on his knowledge. In another scenario, the worker has knowledge about two firms. Then the worker uses these pieces of knowledge to optimise his buying-decision.

Moreover, the workers have knowledge about 3, 4 .., 20 firms, i.e., the model starts by providing each worker agent with information about one firm. In another experiment, the model gives the worker agent information about two firms and so on. On other words, the model experiments with different runs under different level of knowledge that are given to the worker agents.

\section{F. Exit and Entry}

Suppose that firm i faces negative profits, moreover, its income approaches zero. Then the model makes firm i exit the market and replace it by a new one, i.e., each exiting firm is replaced by a new firm which initialised with the average features of those firms still in the market at time $t$. This process allows to keep the number of firms constant at each time.

\section{RESUlts}

This section describes the main results of the ACE model. Quantitative analysis is performed and the results displayed. A simulation has a hundred experiments; each experiment runs an economy for 1000 time steps. The results are taken at time step 1000. In all simulations that follows, we set the number of firms numF=20 and the number of workers num $W=100$.

\section{A. Demand-Pull Inflation}

These experiments depict the demand-pull inflation. Demand-pull inflation happens when, for example, money supply increases, then the equilibrium price point will move to a situation where price is higher than the price in the first place, but the GDP will be the same. This transition happens in two steps. The first step when money supply increases then the demand curve moves to the right, this means the price increases and GDP (Gross Domestic Product) increases. The equilibrium exists when the economy works under full employment (unemployment rate equals natural or target rate). Therefore, when demand increases the economy works above full employment as the result wage responses to this pressure on employment and starts to increase. Consequently, the production cost increases and supply curve moves to the left until reaches to the point when the economy achieves full employment.

Figure 1 depicts the changes in prices when money supply increases. When firms have 300 money supply at the first time step the price ${ }^{2}$ is 40 . When money supply increases then the price level increases to 51 . We calculate the price level as the average of selling prices and GDP before and after money supply increases. There is stability in demandpull results, as noted from the standard deviation being small. In addition, Table 1 shows how changes in money supply change the price level and GDP. GDPs are nearly the same, which means the economy works at full employment. GDP is calculated as the sum of all production multiplied by their prices at time $t$.

Workers may follow one of three job search scenarios. The performance of the economy is affected by these scenarios; all scenarios can produce the demand-pull behaviour while they are different in unemployment rate. In other words, the unemployment rate, in the first scenario, is higher than the unemployment rate if the workers follow the second scenario,and the unemployment rate, in the second scenario, is higher than if workers select the third scenario. Therefore, the performance of the economy is sensitive to the search procedures that workers are followed to search for their new jobs. Moreover, the effect of search scenarios changes the price level because when the unemployment rate high then the production is limited and price is high while the unemployment rate is small then there are huge production that will affect on the price level. Figure 1 depicts the demand-pull inflation when workers select second and third scenarios for search new jobs, respectively.

\section{B. Cost-Push Inflation}

This section depicts the cost-push inflation. Cost-push inflation occurs when wages (production cost) increase. The economy suffers from cost-push inflation if the money supply increases, i.e., if government or central bank intervenes by pushing the economy throughout increases money supply. If central bank does not respond to wage increases, the economy itself reduces the effect of wage fluctuations. Figure

\footnotetext{
${ }^{2}$ We calculate price as the average of all selling-prices.
} 


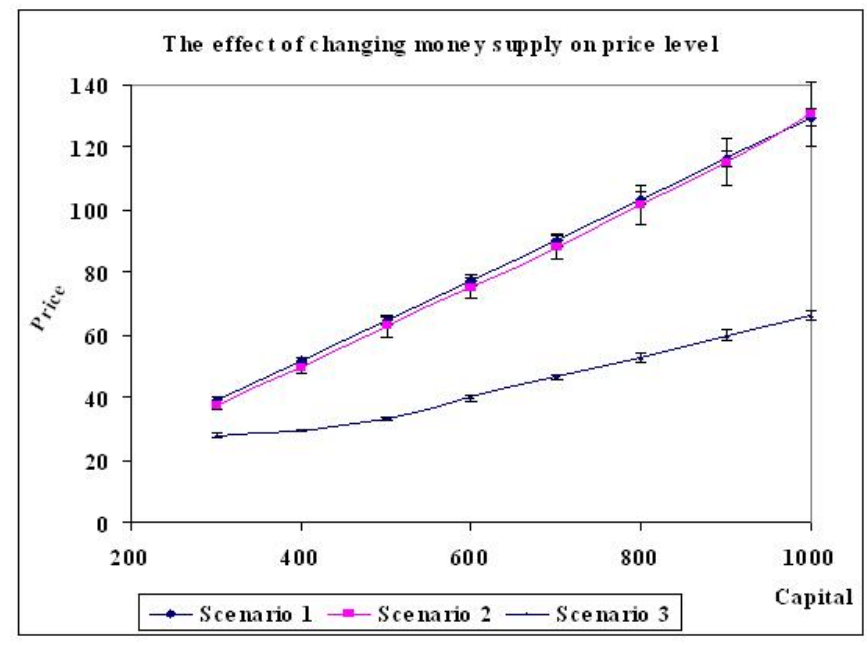

Fig. 1. Price level when money supply increase for three search scenarios

\begin{tabular}{|l|l|l|}
\hline Money Supply & Price & GDP \\
\hline 300 & 39.09 & 148.7 \\
\hline 400 & 51.79 & 150.34 \\
\hline 500 & 64.53 & 148.23 \\
\hline 600 & 77.56 & 149.98 \\
\hline 700 & 90.46 & 149.50 \\
\hline 800 & 103.56 & 149.58 \\
\hline 900 & 116.57 & 149.04 \\
\hline 1000 & 129.60 & 148.66 \\
\hline
\end{tabular}

TABLE I

THE EFFECT OF CHANGING MONEY SUPPLY ON PRICE LEVEL

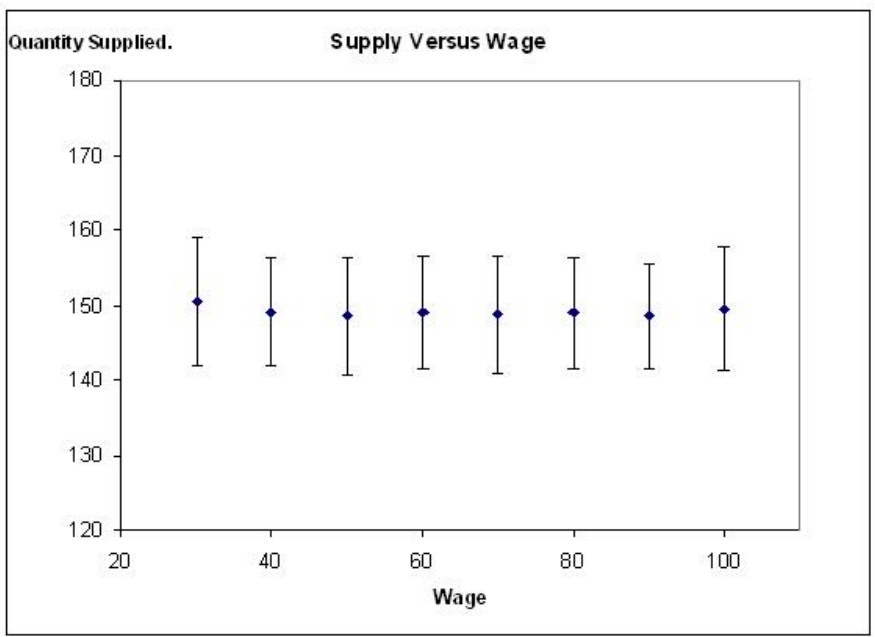

Fig. 2. Wage increases without central bank

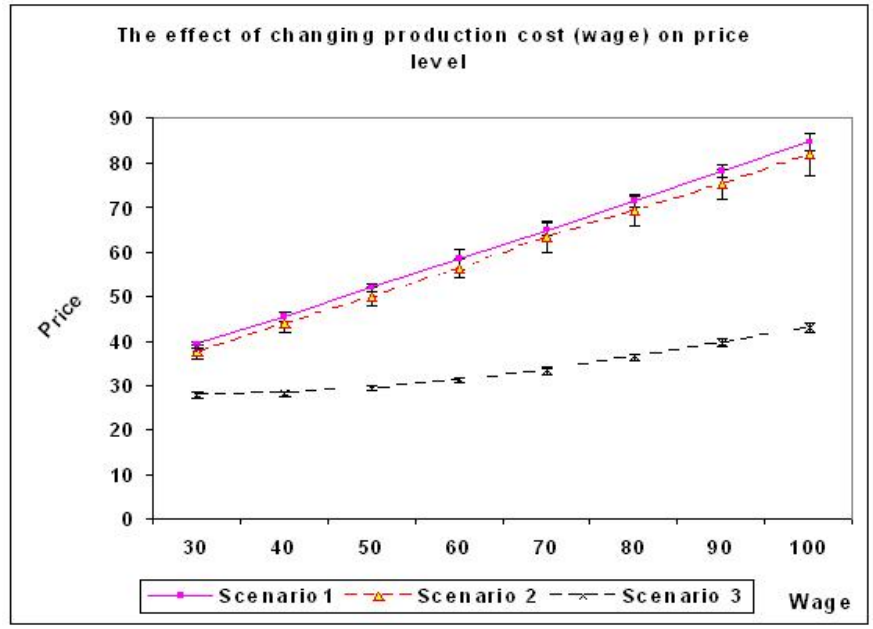

Fig. 3. Cost-Push when Wage increases - search scenarios 1,2 and 3

2 shows that the economy is able to self-organise, i.e., the economy has its mechanisms to diminish the effect of wage increase, while Figure 3 shows the economy when central bank intervenes by increasing money supply.

\section{Effect of The Level of Rationality}

This section describes the effect of amount of knowledge/information that agents have on the equilibrium price and unemployment rate. Knowledge is the only key factor in our model that determines the level of rationality. The model assumes that agents have the computational power to optimise their buying-decision that is, choosing the firm that has the best price and still has production to sell.

The model starts from different level of knowledge which is available to each consumer/worker. Then, a consumer enters the market based on his knowledge and calculates the amount of production that he needs.

The main findings are that the inflation and unemployment rate are effected by the level of rationality/knowledge that the agents posses. Figure 4 and Figure 5 divide the level of rationality $-\mathrm{X}$-axis - into three parts. In the first part, when the level of rationality, i.e., the amount of information that the consumers have about the market, are small, we find that there is a direct, weak relationship between the inflation (the equilibrium price) and the level of rationality, that is, the equilibrium price increases slowly when the information level increase.

Figure 4 and Figure 5 show that there is positive relationship between equilibrium price and the level of rationality as well as the inverse relationship between unemployment rate and rationality. At a low level of rationality, workers neither have enough information about the job vacancies nor wages. Therefore, they are unable to optimize their jobsearch procedures. A significant percent of workers are still unemployed, which will effect the demand side of the goods market, that is push the demand curve to the left, i.e., the price level and production decrease.

Figure 5 shows that when the level of rationality increases, 
the unemployment rate decreases sharply in all scenarios. As a result this means that as the number of employed workers increases, follows that the demand side of the goods market increases resulting in the demand curve moving to the right. As a result the price level and production increase.

In the second part, when there is a moderate information available for the consumer. We find that unemployment rate and equilibrium price follow the same behaviour as first part when the level of rationality increase. The only difference is that unemployment rate in the second scenario starts to reach to the steady state while in the other scenarios is still decreasing.

In the last part, when consumers are nearly to be fully rational or fully rational, unemployment rate reach to the full employment which is the steady state of the economy. We notice that each scenario or economy has its own steady state which is based on its settings. We find that the third scenario reaches low levels of unemployment which are between $2 \%$ and $3 \%$ which equivalent to the unemployment rate in USA, Europe and Japan, while other scenarios have high level of unemployment rate.

In addition, when unemployment rate is small, then the demand side of the goods market increase which move the demand curve to the right, that is, the price level increase, but the production level does not because the economy reaches full employment. Then firms try to hire more workers by increasing wages. On the other side the economy works under full employment. Wage increases push the demand curve to the right, but the economy is unable to increase the supply side then price level increase. All scenarios behave in the same manner in the last part.

Finally, real economic agents are not perfectly rational. For example, economists have limited knowledge on what exactly the natural rate of unemployment is. Moreover, economists specify natural unemployment rate which is an ambiguous variable. Therefore, it will be more accurate if the economists can link between the level of rationality that the economic agents have and what will happen in the economy if some knowledge and/or computational power is hidden or improved.

Figure 6 depicts the relationship between the level of rationality and the equilibrium price level for job-search scenarios 2 and three. Figure 5 shows that scenario 2 and scenario 3 have the behaviour due to the large scale for scenario 1 . Figure 6 shows that both scenarios have positive relationship between the level of rationality and the equilibrium price level, but their behaviour are quite different, for instance, at low level of rationality, the change of the level of rationality does not effect too much in the equilibrium price in scenario 3 while it has more of an effect in scenario 2. At high level of rationality, both scenarios have the behaviour, that is, the change in the level of rationality increases the equilibrium price.

We performed the correlation and regression statistical analysis for the relationships between the level of rationality and unemployment rate and the equilibrium price. We found

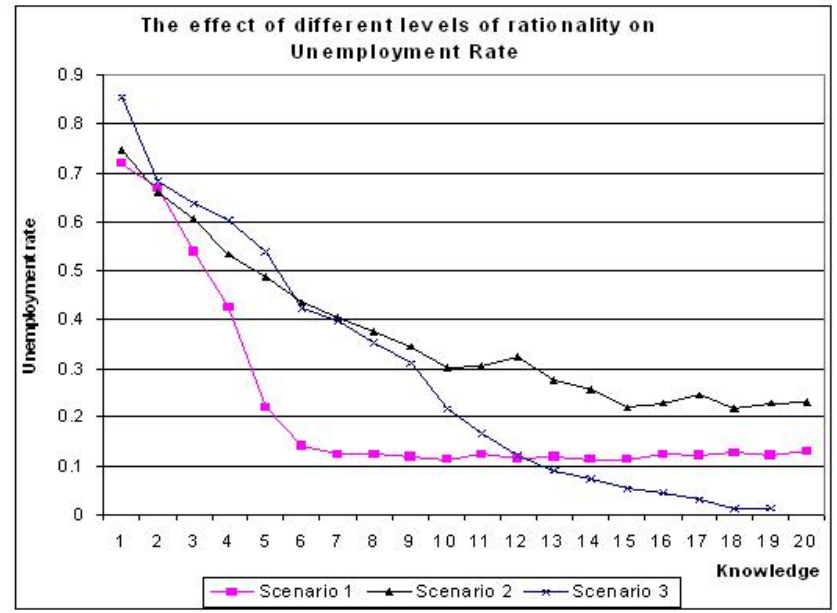

Fig. 4. The effect of different levels of rationality on Unemployment Rate

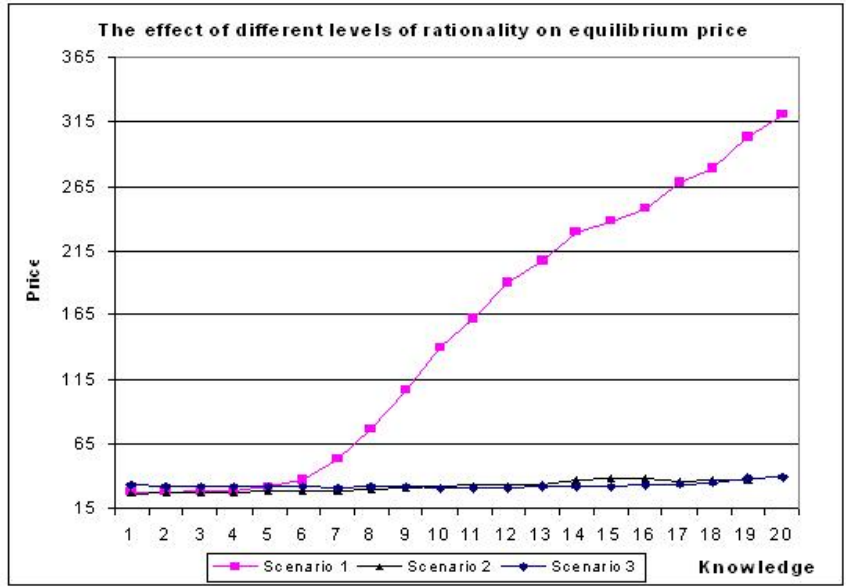

Fig. 5. The effect of different levels of rationality on the equilibrium price

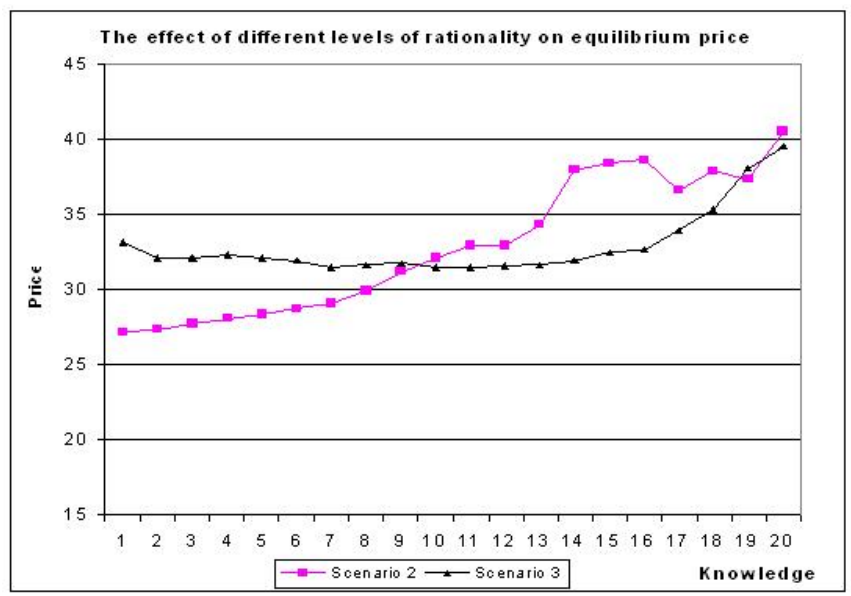

Fig. 6. The effect of different levels of rationality on the equilibrium price -Scenarios 2 and 3 


\begin{tabular}{|l|l|l|}
\hline Scenario & Unemployment rate & Equilibrium price \\
\hline 1 & -0.72 & 0.98 \\
\hline 2 & -0.92 & 0.96 \\
\hline 3 & -0.96 & 0.60 \\
\hline
\end{tabular}

TABLE II

STATISTICAL ANALYSIS FOR THREE SCENARIOS

that there is a significant negative relationship between the level of rationality and unemployment rate with correlation coefficient $-0.72,-0.92$ and -0.95 for scenarios 1,2 and 3 respectively. Table 2 shows the statistical results for the three scenarios. Table 2 shows that there is a significant relationship between the level of rationality and the equilibrium price in all scenarios. Moreover, we performed a regression analysis. we found that the level of rationality effects negatively on unemployment rate, while it effects positively on the equilibrium price level.

The ACE model is able to produce the demand-pull and cost-push inflation without the key assumptions, homogeneous, anonymous and perfectly rational agents, of economic theory. Furthermore, the model shows that the cost-push inflation happens if the money supply is changed by the government. On the other hand, increasing wages do not produce inflation without the government intervening. This result agrees with the monetarist theory by Milton Friedman.

The ACE model allows us to study the effect of different level of rationality on both unemployment rate and the equilibrium price. The model shows that there is negative relationship between the level of rationality and unemployment rate. While there is a positive relationship between the level of rationality and the equilibrium price. An economy may achieve to a certain unemployment rate and certain a equilibrium price, but the resources in the economy may able to push the model to another equilibrium level better than the old position. The economy can not able to move because the level of information is below the level that motivates the economic agents to interact with each to push the economy to better situation.

\section{REFERENCES}

[1] F. Alkemade, “ Evolutionary Agent-Based Economics." PhD thesis, Institute of Programming Research and Algorithmics, 2004.

[2] F. Alkemade, H. L. Poutre, and H. Amman, " Intermediaries in an electronic trade network [extended abstract]." In EC 03: Proceedings of the 4th ACM conference on Electronic commerce, pages 200-201, New York, NY, USA, 2003. ACM Press.

[3] F. Alkemade and J. L. Poutre. "Heterogeneous, boundedly rational agents in the cournot doupoly." Technical report, In: Heterogenous Agents, Interactions and Economic Performance (R. Cowan and N. Jonard, Eds.). Vol. 521 of Lecture Notes in Economics and Mathematical Systems. Springer. pp. 3-17., 2003.

[4] W. B. Arthur. "Inductive reasoning and bounded rationality." American Economic Review, 84(2):406-411, May 1994.

[5] G. Ellison. " Bounded rationality in industrial organization.” Technical report, MIT and NBER, 2006.

[6] J. M. Epstein. " Agent-based computational models and generative social science.” Complexity, 4(5):41-60, 1999.

[7] J. M. Epstein and R. Axtell. " Growing Artificial Societies: Social Science from the Bottom Up." The MIT Press, 1996.
[8] G. Fagiol, G. Dosi, and R. Gabriele. “ Towards an Evolutionary Interpretation of Aggregate Labour Markets Regularities.” Springer Berlin Heidelberg, 2005.

[9] M. Friedman. “ Monetary History of the United States, 1867-1960.“ Princeton University Press, 1971

[10] F. G., D. G., and R. Gabriele. " Matching, bargaining, and wage setting in an evolutionary model of labor market and output dynamics." Advances in Complex Systems, vol 7:157-186, 2004.

[11] D. D. Gatti, E. Gaffeo, M. Gallegati, and A. Palestrini. " The apprentice wizard: monetary policy, complexity and learning." New Mathematics and Natural Computation, Vol. 1, No. 1:109-128, 2005.

[12] S. Josgi, J. Parker, and M. A. Bedau. "Financial markets can be at sub-optimal equilibria." Computational Economics, 19:5-23, 2002.

[13] S. M. Manson. " Bounded rationality in agent-based models: experiments with evolutionary programs." International Journal of Geographical Information Science, vol 20, No 9:991-1012, 2006.

[14] M. Parkin, M. Powell, and K. Matthews. "Economics", Sixth edition. Addison-Wesley, 2005.

[15] D. Phan. " Cognitive Economics: An Interdisciplinary Approach." springer, 2004.

[16] L. Tesfatsion. " Agent-based computational economics: Growing economies from the bottom up." Artificial Life, 8(1):55-82, 2002.

[17] L. Tesfatsion. " Agent-based computational economics: modeling economies as complex adaptive systems." Information Sciences, Volume 149, Issue 4:262-268, 2003.

[18] L. Tesfatsion. " Agent-based Computational Economics: A constructive approach to economic theory", Handbook of Computational Economics, Volume 2: Agent-based Computational Economics, chapter 16, pages 831-877. Elsevier, 2006.

[19] L. Tesfatsion. " Agents come to bits: towards a constructive comprehensive taxonomy of economic entities." Technical report, Economics Department, Iowa State University, 2006.

[20] T. V. Zandt. " Decentralized Information Processing in the Theory of Organizations", chapter 7, pages 125-160. London: MacMillan Press Ltd., 1999. 